CZASOPISMO INŻYNIERII LĄDOWEJ, ŚRODOWISKA I ARCHITEKTURY JOURNAL OF CIVIL ENGINEERING, ENVIRONMENT AND ARCHITECTURE

JCEEA, t. XXXIII, z. 63 (3/16), lipiec-wrzesień 2015, s. 507-516

\author{
Barbara TCHÓRZEWSKA-CIEŚLAK ${ }^{1}$ \\ Dorota PAPCIAK ${ }^{2}$ \\ Jadwiga KALETA ${ }^{3}$ \\ Alicja PUSZKAREWICZ ${ }^{4}$
}

\title{
ANALIZA NIEZAWODNOŚCI STACJI UZDATNIANIA WODY
}

\begin{abstract}
Systemy zbiorowego zaopatrzenia $\mathrm{w}$ wode składają się $\mathrm{z}$ połączonych ze sobą elementów (podsystemów ) stanowiących integralna całość, współpracujących ze sobą w sposób ciągły w celu zapewnienia dla konsumentów wody o odpowiedniej jakości. W przypadku gdy jakość wody w źródle nie odpowiada normatywom stawianym wodzie przeznaczonej do spożycia przez ludzi, woda musi być poddana procesom uzdatniania. Niezawodność funkcjonowania stacji uzdatniania wody jest jednym z podstawowych elementów szeroko rozumianej analizy niezawodności i bezpieczeństwa całego systemu zbiorowego zaopatrzenia w wodę. Niezawodność dostawy wody polega na zapewnieniu stabilnych warunków, umożliwiających pokrycie bieżącego i perspektywicznego zapotrzebowania na wodę w odpowiedniej ilości i wymaganej jakości w dowolnym, dogodnym dla konsumentów wody czasie. W pracy przedstawiono podstawy analizy niezawodności, podano podstawowe miary oraz zasady wykorzystania struktur niezawodnościowych. Obliczenia wykonano dla stacji uzdatniania wody na podstawie schematu niezwodnościowego metodą jednoparametryczną. Na podstawie danych z eksploatacyjnych stacji uzdatniania wody (SUW) wchodzącej w skład systemu zbiorowego zaopatrzenia w wodę miasta liczącego ok 80 tys. mieszkańców sporządzono schemat niewodności stacji oraz przeprowadzono obliczenia wskaźnika gotowości K. W metodzie wykorzystano podstawowe struktury niezawodnościowe. Wyznaczoną miarę niezawodności porównano z wartościami kryterialnymi.
\end{abstract}

Słowa kluczowe: stacja uzdatniania wody, niezawodność, bezpieczeństwo, ryzyko

${ }^{1}$ Autor do korespondencji / corresponding author: Barbara Tchórzewska-Cieślak, Politechnika Rzeszowska, Wydział Budownictwa, Inżynierii Środowiska i Architektury, al. Powstańców Warszawy 6, 35-959 Rzeszów, tel. 17 8651435, cbarbara@prz.edu.pl

2 Dorota Papciak, Politechnika Rzeszowska, Wydział Budownictwa, Inżynierii Środowiska i Architektury, al. Powstańców Warszawy 6, 35-959 Rzeszów

3 Jadwiga Kaleta' Politechnika Rzeszowska, Wydział Budownictwa, Inżynierii Środowiska i Architektury, al. Powstańców Warszawy 6, 35-959 Rzeszów

4 Alicja Puszkarewicz Politechnika Rzeszowska, Wydział Budownictwa, Inżynierii Środowiska i Architektury, al. Powstańców Warszawy 6, 35-959 Rzeszów 


\section{Wprowadzenie}

Systemy zbiorowego zaopatrzenia $\mathrm{w}$ wodę (SZZW) zgodnie $\mathrm{z}$ Ustawą z dnia 17 lipca 2009 r. o zmianie ustawy o zarządzaniu kryzysowym (Dz. U. z 2009 r .Nr 131, poz.1076) należą do infrastruktury krytycznej, a niezawodne i bezpieczne funkcjonowanie wszystkich jego podsystemów od ujęcia wody poprzez jej uzdatnianie oraz dystrybucję do konsumentów warunkują bezpieczeństwo dostawy wody.

Bezpieczeństwo SZZW ma swoje międzynarodowe regulacje prawne, których źródłem są przede wszystkim wytyczne Światowej Organizacji Zdrowia WHO (ang. World Health Organization). W 2004 roku, w trzeciej edycji wytycznych dotyczących jakości wody do spożycia (Guidelines for Drinking-Water Quality), organizacja WHO przedstawiła założenia do opracowania tzw. Planu Bezpieczeństwa Wodnego (ang. Water Safety Plan - WSP), które są przeznaczone dla systemów zbiorowego zaopatrzenia ludności w wodę i które wychodzą naprzeciw wymaganiom odnośnie do ochrony infrastruktury krytycznej.

Stan bezpieczeństwa zwykle jest akceptowany, jeśli system spełnia wymagania bezpieczeństwa sformułowane $w$ przepisach prawnych i normach $[3,8,10,11,12]$.

W odniesieniu do konsumentów wody do spożycia bezpieczeństwo jest rozumiane jako prawdopodobieństwo uniknięcia zagrożenia wynikającego ze spożycia wody o jakości niezgodnej z obowiązującym normatywem lub z braku wody $[1,2,6,8,9,11,12]$. Niezawodność dostawy wody polega na zapewnieniu stabilnych warunków, umożliwiających pokrycie bieżącego i perspektywicznego zapotrzebowania na wodę w odpowiedniej ilości i wymaganej jakości w dowolnym, dogodnym dla konsumentów wody czasie, a także w akceptowalnej przez nich cenie $[5,13]$.

\section{Metodyka badań}

\subsection{Miary niezawodności}

Ilościowo niezawodność systemów opisuje się, wykorzystując do tego celu wskaźniki niezawodności tzw. miary. Są to charakterystyki funkcyjne lub liczbowe uwzględniające właściwości systemu i jego elementów oraz opisujące procesy losowe związane z ich funkcjonowaniem. Wśród wskaźników można wyróżnić wskaźniki o charakterze podstawowym, opisujące prawdopodobieństwo przebywania systemu w stanach niezawodności lub zawodności oraz wskaźniki uzupełniające np. średni czas przebywania systemu w określonych stanach. Do podstawowych wskaźników stosowanych w analizie niezawodności SZW należą $[7,5,13]$. 
Średni czas pracy bezuszkodzeniowej $\mathrm{T}_{\mathrm{p}}$ jest wartością oczekiwaną zmiennej losowej $\mathrm{T}_{\mathrm{p}}$ ' określającej czas pracy (zdatności) systemu (lub jego elementów), między dwoma kolejnymi uszkodzeniami [13].

$$
\mathrm{T}_{\mathrm{p}}=\frac{1}{\mathrm{k}+\mathrm{z}} \cdot\left(\sum_{\mathrm{i}=1}^{\mathrm{k}} \mathrm{t}_{\mathrm{pi}}+\mathrm{z} \cdot \mathrm{t}\right)
$$

t- czas obserwacji,

$\mathrm{t}_{\mathrm{pi}^{-}}$wartość i-tego czasu pracy obiektów uszkadzających się,

k- liczba okresów pracy obiektów uszkadzających się,

z- liczba okresów pracy obiektów nieuszkadzających się

$\mathrm{f}(\mathrm{t})$ - gęstość prawdopodobieństwa zmiennej losowej $\mathrm{T}_{\mathrm{p}}$.

Średni czas naprawy $T_{n}$ jest sumą czasu oczekiwania na naprawę $T_{d} i$ czasu naprawy rzeczywistej (do moment włączenia elementu do eksploatacji) $\mathrm{T}_{0}$.

$$
\mathrm{T}_{\mathrm{n}}=\mathrm{T}_{\mathrm{d}}+\mathrm{T}_{0}
$$

Średni czas naprawy jest wartością oczekiwaną zmiennej losowej $\mathrm{T}_{\mathrm{n}}$ ' określającej czas naprawy.

$$
\mathrm{T}_{\mathrm{n}}=\frac{1}{\mathrm{n}_{\mathrm{O}}} \sum_{\mathrm{i}=1}^{\mathrm{n}_{\mathrm{O}}} \mathrm{t}_{\mathrm{ni}}
$$

$\mathrm{f}_{\mathrm{o}}(\mathrm{t})$ - gęstość zmiennej losowej $\mathrm{T}_{\mathrm{o}}$,

$\mathrm{n}_{\mathrm{o}}$ - liczba napraw $\mathrm{w}$ badanym okresie,

$\mathrm{t}_{\mathrm{ni}} \quad$ - czas trwania $\mathrm{i}$ - tej naprawy.

Intensywność uszkodzeń $\lambda(\mathrm{t})$

$$
\begin{aligned}
& \lambda=\frac{1}{\mathrm{~T}_{\mathrm{ps}}}, \\
& \lambda(\mathrm{t})=\frac{\mathrm{n}(\mathrm{t}, \mathrm{t}+\Delta \mathrm{t})}{\mathrm{N} \cdot \Delta \mathrm{t}}
\end{aligned}
$$

$\mathrm{T}_{\mathrm{pss}-}$ średnia wartość czasu pracy pomiędzy kolejnymi uszkodzeniami, $\mathrm{n}(\mathrm{t}, \mathrm{t}+\Delta \mathrm{t})$ - liczba wszystkich uszkodzeń w przedziale czasu $\Delta \mathrm{t}$,

$\mathrm{N}$ - liczba badanych elementów lub w przypadku systemów liniowych dł. w km, $\Delta \mathrm{t}$ - czas obserwacji.

Intensywność odnowy $\mu(t)$ określa liczbę niesprawności w jednostce czasu, można ją wyznaczyć z danych eksploatacyjnych wg wzoru: 


$$
\mu(t)=\frac{n(t, t+\Delta t)}{n(t) \cdot \Delta t}
$$

$\mathrm{n}(\mathrm{t}, \mathrm{t}+\Delta \mathrm{t})$-liczba elementów, których odnowa zakończyła się w przedziale czasu $(\mathrm{t}, \mathrm{t}+\Delta \mathrm{t})$,

n (t) - liczba elementów, których odnowa zakończyła się do czasu t,

$\Delta \mathrm{t}$-długość okresu obserwacji.

Wskaźnik gotowości $\mathrm{K}(\mathrm{t})$ określa prawdopodobieństwo, że system będzie w stanie niezawodności. Wraz ze wzrostem długości czasu eksploatacji systemu, wartość wskaźnika gotowości $\mathrm{K}(\mathrm{t})$ zmierza do granicznej wartości, która nosi nazwę stacjonarnego wskaźnika gotowości K $[5,7,13]$

$$
K=\lim _{t \rightarrow \infty} K(t)=\frac{\mu}{\mu+\lambda}=\frac{T_{p}}{T_{p}+T n}=\frac{\frac{T_{p}}{T_{n}}}{T_{p} / T_{n}+1}
$$

Wskaźnik zawodności U określa prawdopodobieństwo, że system będzie znajdował się w stanie zawodności.

$$
\mathrm{U}=1-\mathrm{K}
$$

\subsection{Analiza niezawodności układu technologicznego SUW na podstawie schematu technologicznego - metoda jednoparametryczna}

W trakcie sporządzania schematu niezawodnościowego, jego elementy traktuje się jako ogniwa pracujące $\mathrm{z}$ określonym prawdopodobieństwem, określającym zdarzenie pracy bezuszkodzeniowej. Można wyróżnić następujące struktury niezawodnościowe [5,7,13].:

a) Struktura szeregowa- jeżeli uszkodzenie dowolnego elementu powoduje uszkodzenie całego podsystemu, to odpowiadające mu ogniwa niezawodnościowe należy sytuować w szeregowej strukturze niezawodnościowej

Dla struktury szeregowej wskaźnik gotowości $K_{s}$, jest równy iloczynowi niezawodności poszczególnych jej elementów składowych:

$$
\mathrm{K}=\prod_{\mathrm{i}=1}^{\mathrm{n}} \mathrm{K}_{\mathrm{i}}
$$

jeżeli dla każdego „,i”:

$$
\mathrm{K}_{\mathrm{i}}=\mathrm{K}_{\mathrm{o}} \text { to } \mathrm{K}=\mathrm{K}_{\mathrm{o}}{ }^{\mathrm{n}}
$$

$\mathrm{i}=1,2,3, \ldots, \mathrm{n} ., \mathrm{n}-$ liczba elementów. 
b) Struktura progowa- jeżeli uszkodzenie podsystemu następuje z chwilą uszkodzenia „,k" z pośród „,M" wszystkich jednorodnych elementów, to ogniwa niezawodnościowe odpowiadające tym elementom należy sytuować w jednorodnej progowej strukturze typu „M-k z M”

Niezawodność jednorodnej struktury progowej wynosi [13]:

$$
\mathrm{K}_{\mathrm{S}}=\sum_{\mathrm{k}=0}^{\mathrm{k}_{\mathrm{dop}}}\left(\begin{array}{c}
\mathrm{M} \\
\mathrm{k}
\end{array}\right) \cdot \mathrm{K}_{0}^{\mathrm{M}-\mathrm{k}} \cdot \mathrm{K}_{\mathrm{p} 0}{ }^{\mathrm{k}}
$$

gdzie:

k - liczba elementów uszkodzonych,

$\mathrm{k}_{\mathrm{dop}}$ - dopuszczalna liczba elementów uszkodzonych,

$\mathrm{K}_{\mathrm{S}}$ - wskaźnik gotowości struktury progowej,

$\mathrm{K}_{0}$ - wskaźnik gotowości pojedynczego elementu,

$\mathrm{Kp}_{0}$ - wskaźnik postoju pojedynczego elementu

M - liczba wszystkich elementów.

$$
\left(\begin{array}{c}
\mathrm{M} \\
\mathrm{k}
\end{array}\right)=\frac{\mathrm{M} !}{\mathrm{k} !(\mathrm{M}-\mathrm{k}) !} \text { - wartość współczynnika dwumianowego }
$$

c) Struktura równoległa - jeżeli uszkodzenie podsystemu następuje z chwilą uszkodzenia wszystkich jednorodnych elementów, to poszczególne ogniwa odpowiadające tym elementom należy sytuować w równoległej strukturze niezawodnościowej .Struktura równoległa jest szczególnym przypadkiem struktury progowej. Niezawodność struktury wyraża się wzorem:

$$
\mathrm{K}_{\mathrm{S}}=1-\prod_{\mathrm{j}=1}^{\mathrm{M}}\left(1-\mathrm{K}_{\mathrm{j}}\right)
$$

gdzie:

$\mathrm{K}_{\mathrm{S}}$ - wskaźnik gotowości struktury równoległej,

$\mathrm{K}_{\mathrm{j}}$ - wskaźnik gotowości pojedynczego elementu,

M - liczba wszystkich elementów.

\subsection{Wymagane wartości wskaźników niezawodności}

W tabeli 1 przedstawiono wartości wymaganego poziomu niezawodności dla SZW $[4,13]$. 
Tabela 1. Wymagane wartości wskaźnika $\mathrm{K}$

Table 1 . The required values $\mathrm{K}$

\begin{tabular}{|l|c|c|}
\hline \multirow{2}{*}{ Kategoria wodociągu } & $\begin{array}{c}\text { Stopień pokrycia całkowite- } \\
\text { go zapotrzebowania na wodę } \\
{[\%]}\end{array}$ & $\begin{array}{c}\text { Wymagany wskaźnik goto- } \\
\text { wości } \\
\mathbf{K}_{\mathbf{W}}\end{array}$ \\
\hline \multirow{2}{*}{$\begin{array}{c}\text { I- wodociągi duże, liczba } \\
\text { mieszkańców }>500000\end{array}$} & 100 & $\geq 0,9917809$ \\
\cline { 2 - 3 } & $\geq 70$ & $\geq 0,9945206$ \\
\hline $\begin{array}{l}\text { II- wodociągi średnie, liczba } \\
\text { mieszkańców } \\
50 \text { 000-500 000 }\end{array}$ & $<70$ & $\geq 0,9999453$ \\
\cline { 2 - 3 } & 100 & $\geq 0,9835617$ \\
\hline \multirow{2}{*}{$\begin{array}{l}\text { I- wodociági duże, liczba } \\
\text { mieszkańców } \leq 50000\end{array}$} & $\geq 70$ & $\geq 0,9917809$ \\
\cline { 2 - 3 } & $<70$ & $\geq 0,99945421$ \\
\hline
\end{tabular}

\section{Przykład aplikacyjny}

Analizie poddano układ stacji uzdatniania wody podziemnej dla miasta liczącego ok 80 tys. mieszkańców.

Urządzenia wodne do poboru wody to ujęcia pompowe:

- SI w skład którego wchodzi 5 szt. studni wierconych $\left(Q_{\operatorname{emax}} 183 \mathrm{~m}^{3} / \mathrm{h}\right)$.

- S II w skład którego wchodzi 22 szt. studni wierconych $\left(\mathrm{Q}_{\mathrm{emax}}=715 \mathrm{~m}^{3} / \mathrm{h}\right)$.

Projektowana maksymalna wydajność stacji uzdatniania wody(SUW) to $715 \mathrm{~m}^{3} / \mathrm{h}$; średnia roczna np. w 2012/2013 roku wyniosła około $265 \mathrm{~m}^{3} / \mathrm{h}$.

Ujmowana woda kierowana jest do studni zbiorczej (czas zatrzymania 2-4 godziny, w zależności od aktualnej produkcji wody). Następnie woda kierowana jest do „napowietrzalni” (kaskady natleniającej). Tuż pod kaskadą umiejscowione jest dozowanie utleniacza chemicznego jakim jest nadmanganian potasu oraz koagulantu PAX - 18. Kolejnym etapem uzdatniania wody są pionowe komory koagulacyjno - sedymentacyjne o czasie kontaktu 6 - 8 godzin. Czas zatrzymania w osadnikach wynosi kilkanaście godzin. Następnym etapem jest filtracja wody (filtry trójwarstwowe: piasek kwarcowy, wpracowane złoże manganowe, antracyt, prędkość filtracji około $3 \mathrm{~m} / \mathrm{h}$,), a końcowym dezynfekcja za pomocą podchlorynu sodu (rys. 1)

Analizę niezawodności SUW wykonano na podstawie schematu technologicznego oraz danych eksploatacyjnych uzyskanych od przedsiębiorstwa wodociągowego. Symbole na rysunku 2 oznaczają:

Sb- studnia zbiorcza

A - pompownia I st

B - aeratory

C - osadniki poziome

F - filtry

B - pompownia II st

ZB - zbiorniki wody czystej. 


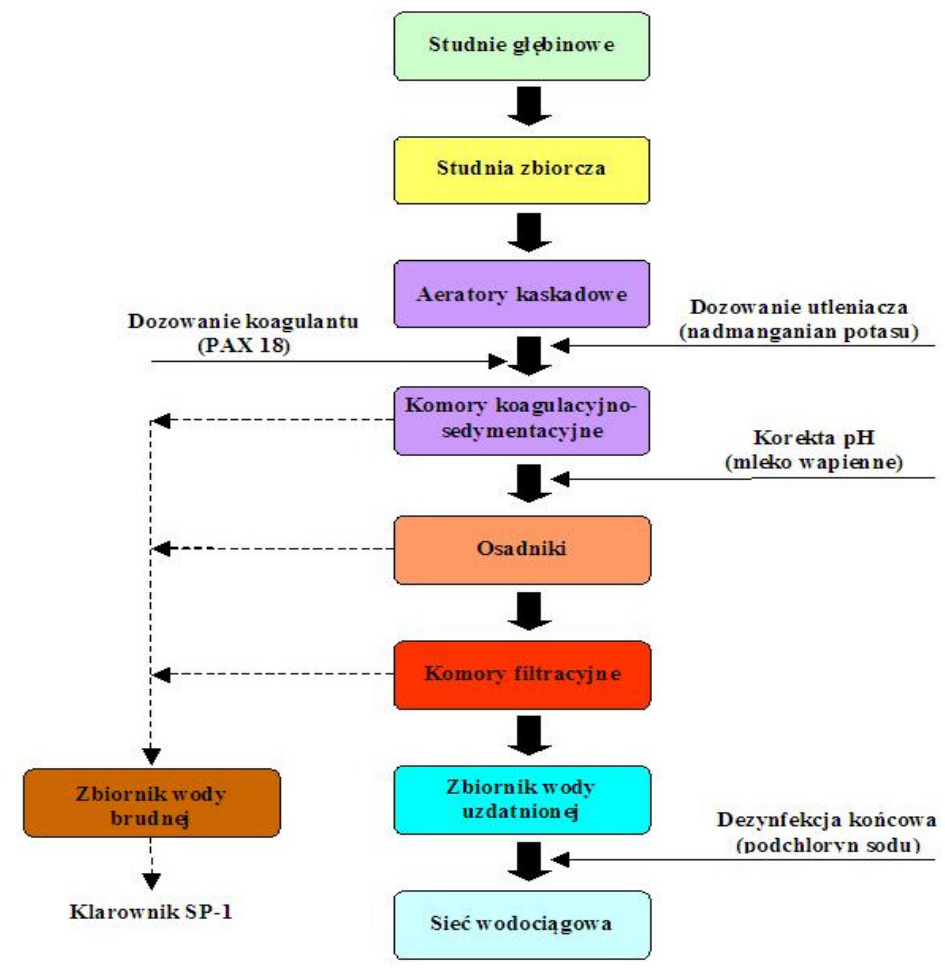

Rys. 1. Schemat technologiczny SUW

Fig. 1. The scheme of water treatment plant

W tabeli 2 zamieszczono wartości wskaźników niezawodności $\mathrm{K}$ dla poszczególnych obiektów SUW. Dla pompowni wartość $\mathrm{K}_{\mathrm{A}}$ wyznaczono na podstawie schematu przedstawionego na rysunku 3. Pozostałe wartości wskaźników przyjęto wg danych literaturowych [5].

Tabela 2. Wartości wskaźników K przyjęte do obliczeń

Table 2. The values of $\mathrm{K}$ index

\begin{tabular}{|c|c|}
\hline Symbol obiektu SUW & K \\
\hline SZb & 0,994 \\
\hline A & 0,988 \\
\hline B & 0,999 \\
\hline C & 0,995 \\
\hline E & 0,961 \\
\hline ZB & 0,988 \\
\hline P1,P2,P3 & 0,994 \\
\hline Z1,Z2,Z3,Z4,Z5,Z6,Z7 & 0,956 \\
\hline ZR1,ZR2,ZR3 & 0,998 \\
\hline
\end{tabular}




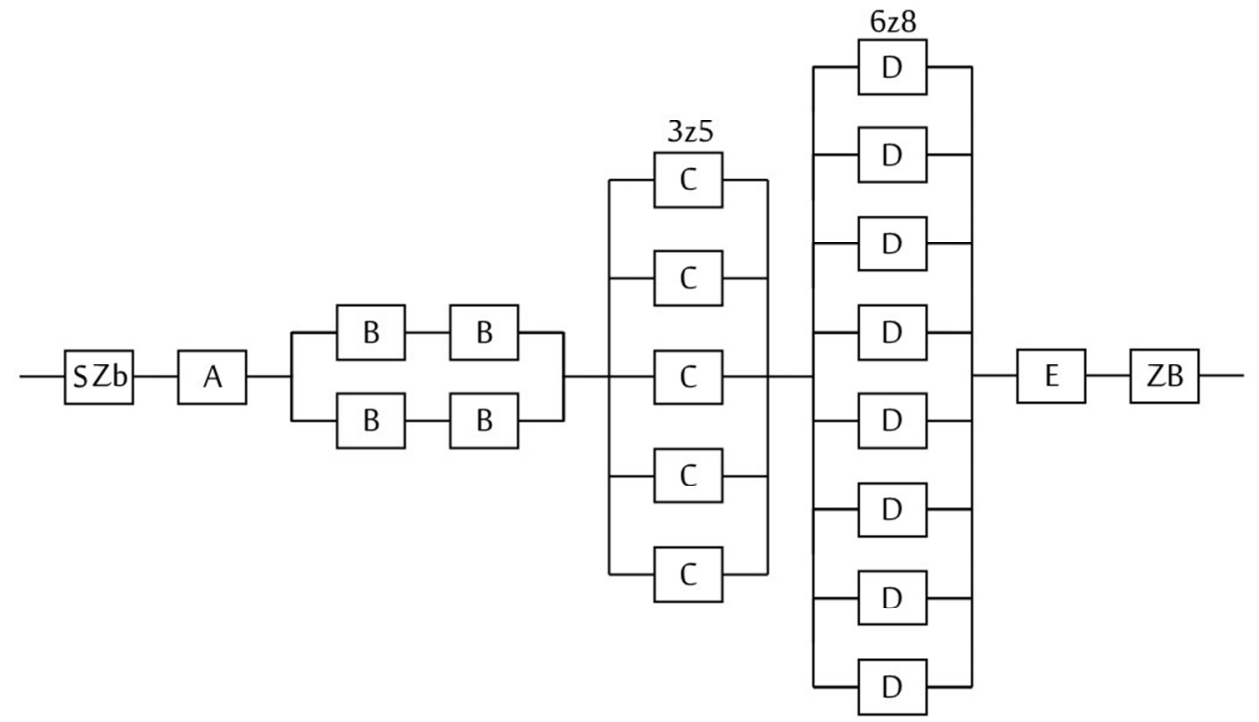

Rys. 2. Schemat niezawodnościowy SUW

Fig. 2. The scheme of WTP

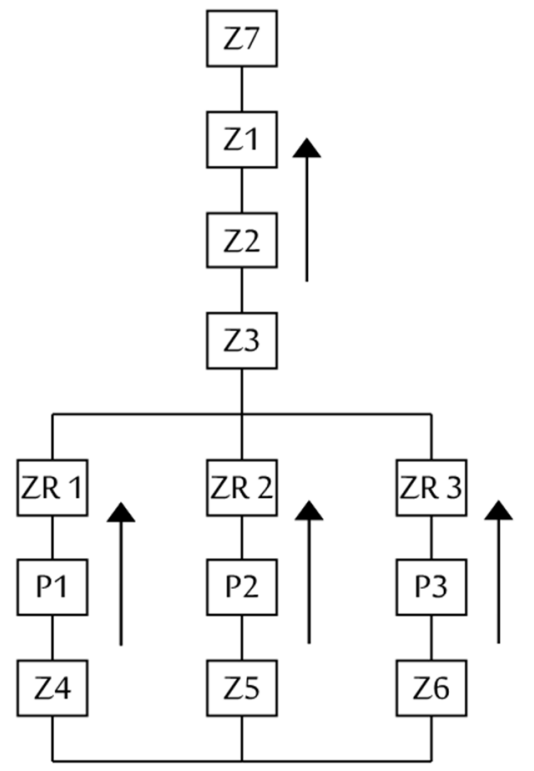

Rys. 3. Schemat niezawodnościowy pompowni

Fig. 3. The scheme of pump station 
Dla pompowni (struktura równoległa $1 \mathrm{z}$ 3), przejęto następujące oznaczenia: P1, P2, P3 - pompy; Z1, Z2, Z3, Z4, Z5, Z6, Z7 - zawory odcinające; ZR1, ZR2, ZR3 - zawory zwrotne

Na podstawie wzorów (9-13) obliczono wartości wskaźników niezawodności $\mathrm{K}$ dla poszczególnych struktur:

- $\mathrm{SZb}$ - A

$$
\mathrm{K}_{\mathrm{SZbA}}=0,994 \cdot 0,998=0,992
$$

$\bullet \mathrm{B}$

$$
\mathrm{K}_{\mathrm{B}}=1-\left[1-(0,999)^{2}\right]^{2}=0,999
$$

- $\mathrm{C} 3 \mathrm{z} 5$

$\mathrm{K}_{\mathrm{pC}=} 1-\mathrm{K}_{\mathrm{C}}$

$\mathrm{K}_{\mathrm{C}}^{\prime}=\left(\begin{array}{c}5 \\ 5-0\end{array}\right) \cdot \mathrm{K}_{\mathrm{C}}^{5-0} \cdot \mathrm{K}_{\mathrm{pC}}^{0}+\left(\begin{array}{c}5 \\ 5-1\end{array}\right) \cdot \mathrm{K}_{\mathrm{C}}^{5-1} \cdot \mathrm{K}_{\mathrm{pC}}^{1}+\left(\begin{array}{c}5 \\ 5-2\end{array}\right) \cdot \mathrm{K}_{\mathrm{C}}^{5-2} \cdot \mathrm{K}_{\mathrm{pC}}^{2}=0,999$

- D 6 z 8

$$
\mathrm{K}_{\mathrm{D}}^{\prime}=\left(\begin{array}{c}
8 \\
8-0
\end{array}\right) \cdot \mathrm{K}_{\mathrm{D}}^{8-0} \cdot \mathrm{K}_{\mathrm{pD}}^{0}+\left(\begin{array}{c}
8 \\
8-1
\end{array}\right) \cdot \mathrm{K}_{\mathrm{D}}^{8-1} \cdot \mathrm{K}_{\mathrm{pD}}^{1}+\left(\begin{array}{c}
8 \\
8-2
\end{array}\right) \cdot \mathrm{K}_{\mathrm{D}}^{8-2} \cdot \mathrm{K}_{\mathrm{pD}}^{2}=0,997
$$

\section{Dla całości: $K=0,9851$}

Analizując wyznaczoną wartość $\mathrm{K} \mathrm{z}$ wartością wymaganymi dla miast o liczbie mieszkańców poniżej 50000 oraz zakładając wymagane $100 \%$ pokrycie zapotrzebowania na wodę $\mathrm{Kw} \geq 0,9671233$ zgodnie $\mathrm{z}$ tab. 1 oceniono, że wskaźnik niezawodności dostawy wody mieści się w wartościach normatywnych.

\section{Wnioski}

- Na podstawie analizy stwierdza się, że wartość wskaźnika niezawodności układu technologicznego SUW mieści się wartościach zalecanych.

- Analiza niezawodności układu technologicznego wykazała, że stopień rezerwowania poszczególnych etapów uzdatniania wody jest wystarczający, a układ technologiczny może pracować również w stanach awaryjnych niektórych urządzeń zapewniając przy tym odpowiednią jakość wody uzdatnionej.

- Można natomiast rozważyć modernizację zbiorników wody czystej.

\section{Literatura}

[1] Aven T.: Reliability and Risk Analysis. Elsevier, London 1992.

[2] Haimes Y.Y., Moser D., Stakhin E.: Risk Based Decision Making in Water Resources. Journal of Infrastructure Systems, ASCE, 12, 2006, s. 401-415.

[3] Hrudey S.E.: Drinking water quality - a risk management approach. Water, 26(1), 2001, s. 29-32.

[4] Iwanejko R.: Preliminary analysis of risks attributed to operation of small surface water intakes. Mat. konf. „Water Supply and Water Quality”, Wydawn. PZiTS O/Wielkopolski, Poznań-Gniezno, I, 2008, s. 229-239. 
[5] Kwietniewski M., Roman M., Kłos-Trębaczkiewicz H.: Niezawodność wodociągów i kanalizacji. Arkady, Warszawa 1993.

[6] Rak J.: A study of the qualitative methods for risk assessment in water supply systems. Environment Protection Engineering, Wydawn. Politechniki Wrocław-skiej, z. 3-4, s. 123-134, 2003.

[7] Rak J.: Niezawodność systemu uzdatniania wód powierzchniowych. Zeszyty Naukowe Politechniki Rzeszowskiej, nr 111, Inżynieria Środowiska, z. 20, Oficyna Wydawnicza Politechniki Rzeszowskiej, Rzeszów 1993.

[8] Rak J.: Podstawy bezpieczeństwa systemów zaopatrzenia w wodę. PAN, Komitet Inżynierii Środowiska, t. 28, Lublin 2005.

[9] Rak J.: Selected problems of water supply safety. Environmental Protection Engineering, Wydawn. Politechniki Wrocławskiej, 35, 2009, s. 29-35.

[10] Rak, J., Pietrucha-Urbanik, K. New directions for the protection and evolution of water supply systems - smart water supply. Czasopismo Inżynierii Lądowej, Środowiska i Architektury - Journal of Civil Engineering, Environment And Architecture. JCEEA, z. 62 (3/I/2015), pp. 365-373. DOI: 10.7862/rb.2015.121.

[11] Rak J, Tchórzewska-Cieślak B.: Ryzyko w eksploatacji systemów zbiorowego zaopatrzenia w wodę. Wydawnictwo Sidel-Przywecki, 2013, s. 1-164.

[12] Tchórzewska-Cieślak B. Metody analizy i oceny ryzyka awarii podsystemu dystrybucji wody. Oficyna Wydawnicza Politechniki Rzeszowskiej. Rzeszów 2011. s. 1-217.

[13] Wieczysty A., Iwanejko R., Lubowiecka T.: Podnoszenie niezawodności działania komunalnych systemów zaopatrzenia w wodę. Metody oceny podnoszenia niezawodności działania komunalnych systemów zaopatrzenia w wodę. PAN, Wydawn. Komitetu Inżynierii Środowiska PAN, Lublin 2001.

\section{ANALYSIS OF RELIABILITY OF WATER TREATMENT STATION}

\section{S u m m a r y}

Collective water supply systems (CWSS) consist of interconnected elements (subsystems) constitute an integral whole, working together on a continuous basis to ensure consumers of water of appropriate quality. If the water quality does not match the source normative values posed water intended for human consumption, the water must be subjected to treatment processes. Reliability of the water treatment plant is one of the basic elements of the broader analysis of reliability and safety of the entire system of collective water supply. The reliability of water supply is to ensure stable conditions, allowing to cover the current and prospective demand for water in sufficient quantity and quality required at any convenient time for water consumers. The paper presents the basics of reliability analysis, are given basic measures and the rules for the use of structures reliability. Calculations were made for the water treatment plant on the basis of the reliability scheme one way method. Based on data from the operating water treatment plants (WTP), which is part of a system of collective water supply a city of about 80 thousand. residents prepared reliability scheme station and the calculations of the indicator K. Method uses the basic structure reliability. The determined reliability as compared with the values of criteria.

Keywords: water treatment, reliability, security, risk

DOI: $10.7862 / \mathrm{rb} .2016 .234$

Przestano do redakcji: $24.06 .2016 r$.

Przyjęto do druku: 30.11.2016 r. 